\title{
Pearls \& Oy-sters: Cyclic Seizures and Heart Rate Variability
}

David Hammer, MD, Mark Scheuer, MD, and Joanna Fong-Isariyawongse, MD

Neurolog ${ }^{\circledR}$ 2021;96:e1694-e1696. doi:10.1212/WNL.0000000000011317
Correspondence

Dr. Fong-Isariyawongse

fongjs@upmc.edu

\section{Pearls}

- Tachycardia in the intensive care unit (ICU) setting is a common and early response in critically ill patients to impending cardiorespiratory instability.

- Cyclic seizures are one cause of episodic tachycardia in the ICU setting.

\section{Oy-sters}

- Seizures should be in the differential diagnosis of unexplained vital sign changes, including tachycardia, apnea, and blood pressure changes.

- It should also be noted that heart rate variability is rarely the only sign of nonconvulsive seizures. A thorough physical examination should always be performed when nonconvulsive status epilepticus is suspected.

A 61-year-old woman with a history of deep vein thrombosis treated with warfarin was evaluated by emergency medical services for a complaint of headache and dizziness beginning while she was at work. Family reported that she had fallen down a step earlier that day. She became unresponsive on her way to the local hospital and was intubated and sedated upon arrival in the emergency department. Her international normalized ratio (INR) was noted to be 5.0. A CT head was performed and the patient was noted to have bilateral acute subdural hematomas, larger on the left, with $10 \mathrm{~mm}$ of left to right midline shift. She was given vitamin $\mathrm{K}$ and prothrombin complex concentrate. She was then transferred to University of Pittsburgh Medical Center (UPMC) Presbyterian Hospital for further evaluation and treatment. Upon arrival to UPMC, the patient was normocardic and normotensive. Examination revealed a Glasgow Coma Scale score of 5T (M3, V1T, E1). INR was rechecked and found to be 1.3. The patient was taken emergently to the operating room for a left sided craniotomy. CT head after the operation revealed a 6-7 $\mathrm{mm}$ residual left to right midline shift.

After the procedure, the patient was monitored in the ICU, where her examination improved to a Glasgow Coma Scale score of 10T (M6, V1T, E3) upon arrival. Prophylactic phenytoin was started with close monitoring to achieve therapeutic levels. In the next 2 days, sedation was weaned, and the patient was extubated. However, as the examination became more reliable, she was noted to have a left upper extremity pronator drift, a finding that raised alarms given the predominantly left hemispheric bleed. Vital signs revealed heart rates ranging from 70 to 104 . There was no evidence of an abnormal breathing pattern. Repeat CT head showed no evidence of acute bleeding and MRI did not reveal the presence of any other lesions. Continuous EEG monitoring was ordered on day 3 of admission.

EEG revealed near-continuous cyclic patterns consisting of brief to intermediate runs (approximately 1 per minute) of high amplitude sharply contoured theta activity maximal over the right hemisphere often with evolution to sharply contoured lateralized rhythmic delta activity (LRDA + S) alternating with relatively benign-appearing alpha/theta activities. These runs were concerning for cyclic focal seizures due to the presence of evolution in morphology (as above), distribution

From the Department of Neurology (D.H., J.F.-I.), University of Pittsburgh Comprehensive Epilepsy Center (UPCEC), University of Pittsburgh Medical Center, PA; and Persyst Development Corporation (M.S.), Solana Beach, CA.

Go to Neurology.org/N for full disclosures. Funding information and disclosures deemed relevant by the authors, if any, are provided at the end of the article. 
(left hemispheric spread), and rhythmicity (emergence of rhythmic delta pattern). Interestingly, cyclical heart rate fluctuations (variations of 10-20 beats per minute) were noted on both EEG and quantitative EEG analysis (Persyst, version 14), which had tight temporal correlation with the cyclic seizures (figure). Levetiracetam and lacosamide were loaded with resolution of concerning EEG activity and corresponding tachycardia and improvement in mental status was noted.

\section{Discussion}

Cyclic seizures were first described in 2008 when the pattern was identified in 13 critically ill patients using compressed spectral array technology. ${ }^{1}$ They have been defined as seizures recurring at regular intervals at a frequency of at least 3 events per hour. This seizure pattern is reasonably common and was seen in $15 \%$ of patients with electrographic seizures on continuous EEG monitoring in one study. ${ }^{2}$ It has been speculated that cyclic seizures may be the result of a failure of seizure termination mechanisms. ${ }^{3}$ These mechanisms include neuronal hyperpolarization, depletion of energy substrates such as ATP, and alterations in levels of neurotransmitters such as GABA and glutamate. ${ }^{4}$ Pauses in seizure activity may represent a refractory period during which the resting metabolic state can be partially restored, a process that circumvents typical seizure termination mechanisms and enables the prolongation of the disease state.

Figure EEG and Quantitative EEG Sample

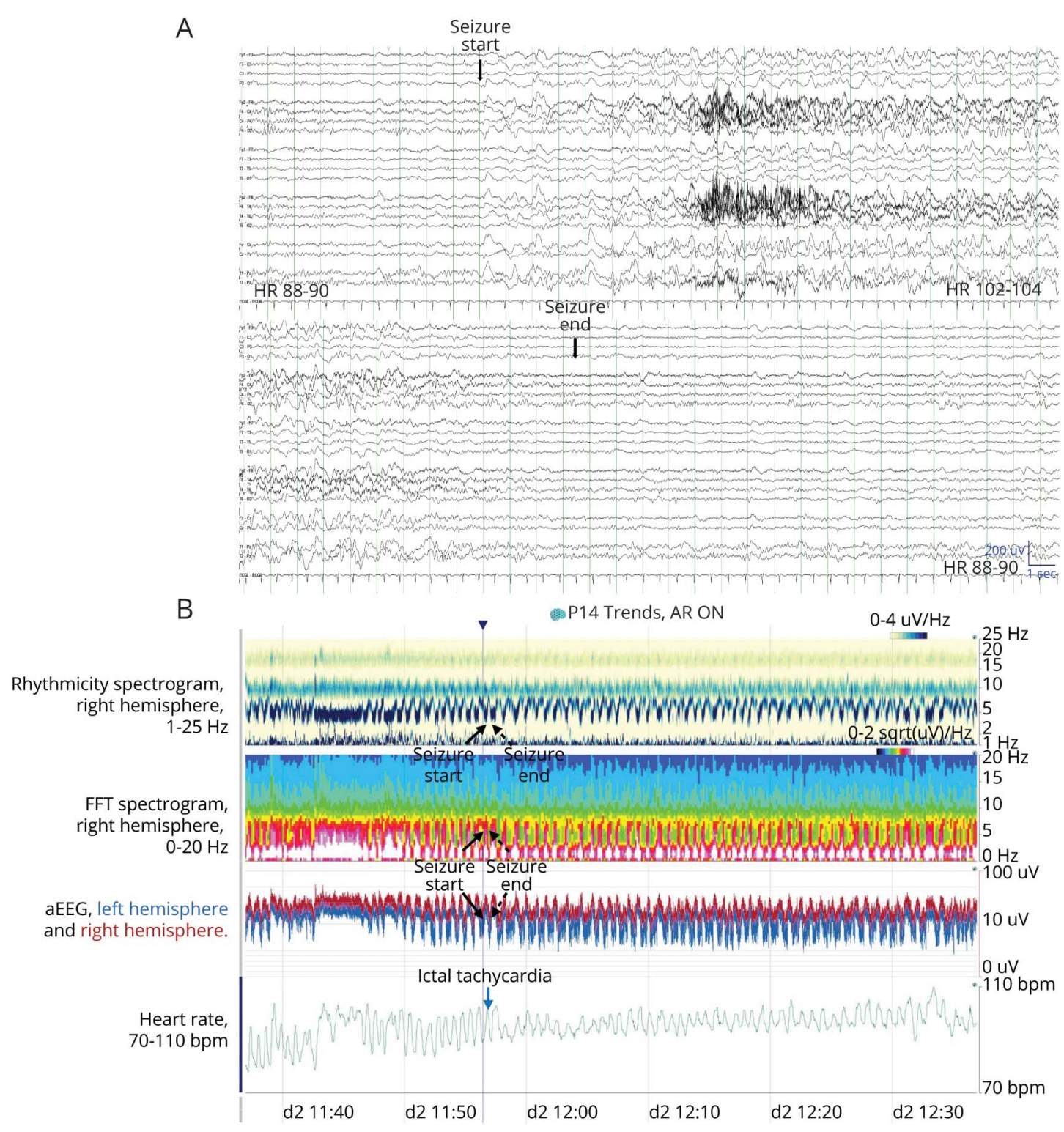

(A) One minute of sample EEG (contiguous 30 seconds sequences shown). Note initial baseline EEG with emergence of high amplitude sharply contoured delta/theta activities (seizure start) corresponding with increase in heart rate. (B) One hour of analysis with Persyst EEG software. Trends from top to bottom: (1) rhythmicity spectrogram, right hemisphere; (2) Fast Fourier transform (FFT) spectrogram, right hemisphere; (3) amplitude-integrated EEG (aEEG) (right = red, blue = left); (4) heart rate. Note the cyclic tachycardia on heart rate trend corresponding to the cyclic ictal changes in the rhythmicity, FFT, and aEEG trends. 
In this case, the patient presented with an acute subdural hematoma, a diagnosis associated with substantial seizure risk. Studies have reported a seizure incidence of $22 \%-28 \%$ in patients with acute subdural hematoma. ${ }^{5,6}$ However, even had the patient's presenting complaint not carried an elevated risk of seizures, nonconvulsive seizures are common in the ICU. In one prospective study of comatose patients without clinical signs of seizures, $8 \%$ met EEG criteria for nonconvulsive status epilepticus (NCSE). ${ }^{7}$ NCSE can be a challenging diagnosis to make and it is therefore important to be cognizant of warning signs for this diagnosis.

Heart rate changes, especially tachycardia, are a common feature in seizures. The process by which the cerebral cortex controls the autonomic nervous system is poorly understood. Recent work has suggested that the anterior insula and cingulate gyrus play crucial roles in this control. ${ }^{8}$ There is additional evidence that the left (dominant) hemisphere predominantly controls parasympathetic output while the right (nondominant) hemisphere controls sympathetic output. ${ }^{8}$

Although the pathways of autonomic system control remain poorly elucidated, there is strong epidemiologic evidence for autonomic changes in the majority of patients who experience seizures. Vagal nerve stimulator studies have suggested that ictal tachycardia is a feature in over $90 \%$ of patients with seizures. ${ }^{9}$ While it is unclear if these numbers are similar in the ICU, unexplained vital sign fluctuations, including tachycardia, blood pressure changes, and apnea, have been recognized as indications for continuous EEG monitoring in the critically ill patient. ${ }^{10}$

This case is an example of episodic tachycardia corresponding to cyclic seizure activity. It provides evidence of the importance of maintaining a high suspicion for seizures in patients with unexplained vital sign changes in the critical care setting.

\section{Study Funding}

No targeted funding reported.

\section{Disclosure}

M. Scheuer is an employee of Persyst Development Corporation. D. Hammer and J. Fong-Isariyawongse report no disclosures relevant to the manuscript. Go to Neurology.org/ $\mathrm{N}$ for full disclosures.

\section{Appendix Authors}

\begin{tabular}{lll}
\hline Name & Location & Contribution \\
\hline $\begin{array}{l}\text { David Hammer, } \\
\text { MD }\end{array}$ & $\begin{array}{l}\text { University of } \\
\text { Pittsburgh Medical } \\
\text { Center, PA }\end{array}$ & $\begin{array}{l}\text { Review of data and primary } \\
\text { author }\end{array}$ \\
\hline $\begin{array}{l}\text { Mark Scheuer, } \\
\text { MD }\end{array}$ & $\begin{array}{l}\text { Persyst Development } \\
\text { Corporation, CA }\end{array}$ & $\begin{array}{l}\text { Primary role in creating } \\
\text { figure, revision of } \\
\text { manuscript }\end{array}$ \\
\hline $\begin{array}{l}\text { Joanna Fong- } \\
\text { Isariyawongse, } \\
\text { MD }\end{array}$ & $\begin{array}{l}\text { University of } \\
\text { Pittsburgh Medical } \\
\text { Center, PA }\end{array}$ & $\begin{array}{l}\text { Creating figure, drafting } \\
\text { and revision for intellectual } \\
\text { content }\end{array}$ \\
\hline
\end{tabular}

\section{References}

1. Friedman DE, Schevon C, Emerson RG, Hirsch LJ. Cyclic electrographic seizures in critically ill patients. Epilepsia 2008;49:281-287.

2. Pinto LF, Gilmore EJ, Petroff OA, et al. Cyclic seizures in critically ill patients: clinical correlates, DC recordings and outcomes. Clin Neurophysiol 2017;128: 1083-1090.

3. Ghoshal S, Reynolds AS, Claassen J. Cyclic seizures: a clue to seizure termination? Clin Neurophysiol 2017;128:1034-1036.

4. Lado FA, Moshé SL. How do seizures stop? Epilepsia 2008;49:1651-1664.

5. Rabinstein AA, Chung SY, Rudzinski LA, Lanzino G. Seizures after evacuation of subdural hematomas: incidence, risk factors, and functional impact. J Neurosurg 2010;112:455-460.

6. Won SY, Konczalla J, Dubinski D, et al. A systematic review of epileptic seizures in adults with subdural haematomas. Seizure 2017;45:28-35.

7. Benbadis SR, Tatum WO, Towne AR, Waterhouse EJ, Garnett L. Prevalence of nonconvulsive status epilepticus in comatose patients. Neurology 2000;55: $1421-1423$.

8. Guo CC, Sturm VE, Zhou J, et al. Dominant hemisphere lateralization of cortical parasympathetic control as revealed by frontotemporal dementia. Proc Natl Acad Sci USA 2016;113:E2430-E2439.

9. Chen W, Meng F. Ictal heart rate changes and the effects of vagus nerve stimulation for patients with refractory epilepsy. Neuropsychiatr Dis Treat 2017;13:2351-2356.

10. Herman ST, Abend NS, Bleck TP, et al. Consensus statement on continuous EEG in critically ill adults and children, part I. J Clin Neurophysiol 2015;32:87-95. 


\title{
Neurology
}

\author{
Pearls \& Oy-sters: Cyclic Seizures and Heart Rate Variability \\ David Hammer, Mark Scheuer and Joanna Fong-Isariyawongse \\ Neurology 2021;96;e1694-e1696 Published Online before print December 4, 2020 \\ DOI 10.1212/WNL.0000000000011317
}

This information is current as of December 4, 2020

\begin{abstract}
Updated Information \&
Services

including high resolution figures, can be found at:

http://n.neurology.org/content/96/12/e1694.full

References

This article cites 10 articles, 2 of which you can access for free at: http://n.neurology.org/content/96/12/e1694.full\#ref-list-1

Permissions \& Licensing

Information about reproducing this article in parts (figures,tables) or in its entirety can be found online at:

http://www.neurology.org/about/about_the_journal\#permissions

Reprints Information about ordering reprints can be found online:

http://n.neurology.org/subscribers/advertise
\end{abstract}

Neurology ${ }^{\circledR}$ is the official journal of the American Academy of Neurology. Published continuously since 1951 , it is now a weekly with 48 issues per year. Copyright @ 2020 American Academy of Neurology. All rights reserved. Print ISSN: 0028-3878. Online ISSN: 1526-632X.

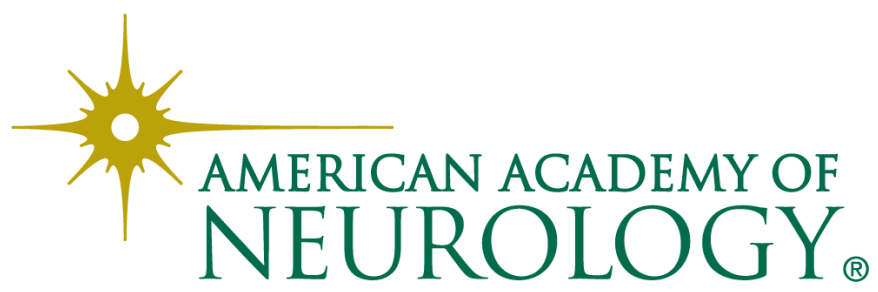

